\title{
Preference for Telemedicine Versus In-Person Visit Among Patients with Psoriasis Receiving Biological Drugs
}

\author{
Paolo Gisondi (D) · Francesco Bellinato · Stefano Piaserico · \\ Sara Di Leo · Simone Cazzaniga · Luigi Naldi
}

Received: April 17, 2021 / Accepted: May 15, 2021 / Published online: June 25, 2021

(C) The Author(s) 2021

\section{ABSTRACT}

Introduction: The use of telemedicine has significantly increased since the outbreak of the SARS-CoV-2 pandemic. In the dermatological setting, patients with stable plaque psoriasis on maintenance therapy with biological drugs may be suitable candidates for telemedicine, although their preference for telemedicine has not yet been investigated. The aim of this study was to investigate the preference for telemedicine versus in-person visit among patients

Supplementary Information The online version contains supplementary material available at https:// doi.org/10.1007/s13555-021-00555-3.

P. Gisondi $(\bowtie) \cdot$ F. Bellinato

Section of Dermatology and Venereology,

Department of Medicine, University of Verona,

Piazzale A. Stefani 1, 37126 Verona, Italy

e-mail: paolo.gisondi@univr.it

S. Piaserico

Section of Dermatology, Department of Medicine,

University of Padua, Padua, Italy

S. Di Leo · L. Naldi

Division of Dermatology, San Bortolo Hospital,

Vicenza, Italy

S. Cazzaniga $\cdot$ L. Naldi

Centro Studi GISED, Bergamo, Italy

S. Cazzaniga

Department of Dermatology, Inselspital University

Hospital of Bern, Bern, Switzerland with psoriasis receiving biological drugs and the reported reasons behind their preferences.

Methods: Consecutive adult patients with chronic plaque psoriasis in stable clinical remission (Psoriasis Area Severity Index $[\mathrm{PASI}] \leq 3$ for at least 12 months) receiving maintenance biological therapy answered a survey investigating whether they would choose telemedicine or inperson visit for the next scheduled visit and the reasons behind their preference. The survey was undertaken through a questionnaire that was developed according to a structured process.

Results: Of the 246 participants in the survey, $118(48 \%)$ preferred telemedicine over an inperson visit for their next scheduled visit with a dermatologist. Multivariate logistic regression analysis revealed that previous experience with digital video-communication tools was a significant predictor for the preference for telemedicine (odds ratio [OR] 10.75; 95\% confidence interval [CI] 3.61-32.03), while older age ( $<60$ years) was negatively associated with the preference for telemedicine (OR 0.30; 95\% CI 0.10-0.90). The most common reasons (75\%) for preferring telemedicine were saving time and safety in relation to the risk presented by the Sars-CoV-2 pandemic (38\%). In contrast, $56 \%$ of the patients who preferred the in-person visit option declared that they were unable to use video-communication tools.

Conclusion: About half of the patients with stable psoriasis receiving biological drugs may be good candidates for telemedicine. 


\section{Graphic abstract:}

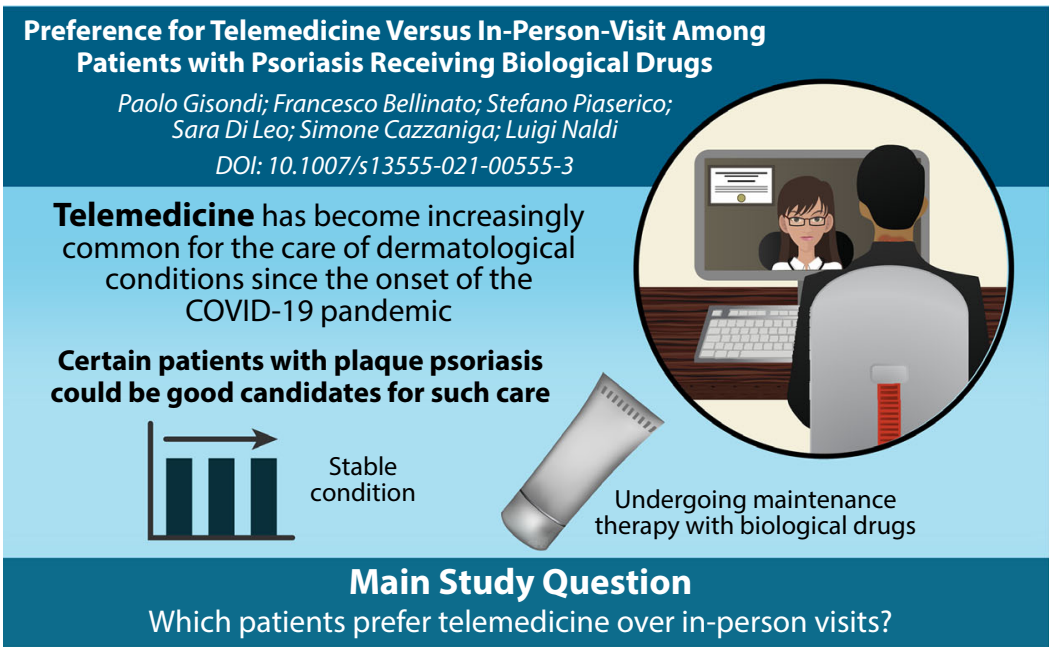

\begin{tabular}{lll}
$\begin{array}{c}\text { Multicenter, } \\
\text { cross-sectional study }\end{array}$ & Part 1: Socio-demographics \\
Questionnaire used & - Sex & - Frequency of dermatological \\
as primary tool & - Age & follow-up \\
& - Biological type & - Distance from hospital \\
\hline & - Education & - Need for accompaniment \\
- Occupation & - Experience with telemedicine and \\
& & video communication tools
\end{tabular}

Part 2: Telemedicine preference

- Would you prefer to have your next follow-up visit in person or with telemedicine?

- What are your reasons for this preference?

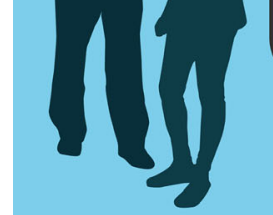

Overall, 246 patients
were recruited

(120 men and 125 women)

Relatively young age

Relatively young age

(49.3 vs 56.7 years)
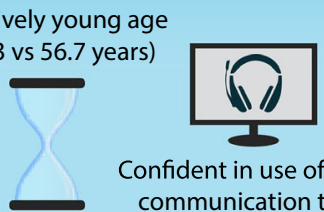

Confident in use of video

communication tools

\section{Why do they prefer telemedicine?}

\section{Inclusion criteria}

$>18$ years of age

Diagnosis of chronic

plaque psoriasis

\section{Stable clinical remission}

Maintenance treatment with licensed biological drug

Preference for telemedicine was found to be strongly associated with certain patient characteristics

\section{Relatively high} educational level

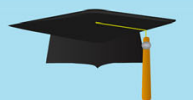

Managerial job
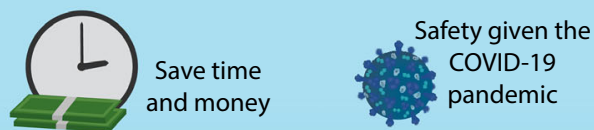

Inability to use video communication tools is the main barrier

Almost half of patients with stable psoriasis receiving biological drugs may be good candidates for telemedicine.

Providing patients with training in telecommunication may increase patient preferences for such care.
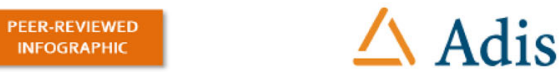

$\square$ OPEN

\section{INFOGRAPHIC}

This infographic represents the opinions of the authors. For a full list of declarations, including funding and author disclosure statements, please see the full text online. (c) The authors, CC-BY-NC 2021 
Keywords: Telemedicine; Teledematology; Inperson visit; Psoriasis; COVID-19; Biological drug

\section{Key Summary Points}

Telemedicine allows the delivery of healthcare services using communication technologies and its use has significantly increased since the outbreak of the SarsCoV-2 pandemic.

Patients with stable chronic plaque psoriasis receiving biological drugs may be good candidates for telemedicine.

The most common reasons of patients for preferring telemedicine is saving time and safety in relation to the risk of SARS-CoV-2 pandemic, whereas the inability to use video-communication tools is a barrier to the use of telemedicine.

\section{DIGITAL FEATURES}

This article is published with digital features, including an infographic, to facilitate understanding of the article. To view digital features for this article go to https://doi.org/10.6084/ m9.figshare.14587893.

\section{INTRODUCTION}

The SARS-Cov-2 pandemic has profoundly revolutionized the management of in-person care of patients affected by chronic conditions because of the many restrictions for elective and non-urgent visits [1]. The use of telemedicine has significantly increased since the outbreak of the COVID-19 pandemic, with the aim of providing continuous patients care [2-4]. Telemedicine allows the delivery of healthcare services using information and communication technologies which enable the sharing of valid information for the diagnosis, treatment and prevention of disease [5]. In the dermatological context there is a need to identify those patients who may be good candidates for telemedicine. It could be hypothesized that patients with plaque psoriasis in stable clinical remission with maintenance biological therapy could be good candidates for telemedicine, but the attitude of this patient group toward telemedicine has not yet been investigated. Therefore, the primary objective of this study was to investigate the preference for telemedicine versus the in-person visit among patients with psoriasis receiving biological drugs and the reported reasons behind their preferences.

\section{METHODS}

This was a multicenter, cross-sectional study based on a questionnaire as the primary tool. Consecutive patients with chronic plaque psoriasis treated with biological drugs attending the University Hospital of Verona and Padua between 1 September 2020 and 1 February 2021 were considered eligible. Inclusion criteria were age $>18$ years, clinically confirmed diagnosis of chronic plaque psoriasis, maintenance treatment with a licensed biological drug (i.e. tumor necrosis factor alpha [TNF- $\alpha]$, interleukin [IL]17A, IL-23 or IL-12/23 inhibitors), stable clinical remission (Psoriasis Area Severity Index [PASI] $\leq 3$ for at least 12 months of continuous treatment). Exclusion criteria were diagnosis of nonplaque psoriasis, such as pustular or erythrodermic psoriasis, treatment with biological drugs administered intravenously (i.e. infliximab), active psoriasis (emergence of new lesions in the last 6 months), cognitive dysfunction that might prevent understanding of the questionnaires or diagnosis of psoriatic arthritis.

\section{The Questionnaire}

The questionnaire was developed according to a structured process that followed several steps. First, a series of open interviews were carried out with a small group of volunteer patients with psoriasis $(n=10)$ in order to select the items to be included in the first draft of the 
Table 1 Sociodemographic and clinical characteristics of the 246 study participants, stratified by their preference for telemedicine versus in-person visit

\begin{tabular}{|c|c|c|c|}
\hline & $\begin{array}{l}\text { Patients who preferred } \\
\text { telemedicine }(n=118,47 \%)\end{array}$ & $\begin{array}{l}\text { Patients who preferred in-person } \\
\text { visit }(n=128,52 \%)\end{array}$ & $P$ value* \\
\hline Sex (male/female) & $65 / 53$ & $55 / 72$ & 0.065 \\
\hline Age (years) & $49.3 \pm 14.3$ & $56.7 \pm 13.2$ & $<0.001$ \\
\hline PASI & $1.2 \pm 0.4$ & $1.3 \pm 0.3$ & 0.924 \\
\hline \multicolumn{4}{|l|}{ Biological drug } \\
\hline TNF- $\alpha$ inhibitors & $34(29)$ & $40(31)$ & 0.917 \\
\hline IL-17A inhibitors & $44(37)$ & $46(36)$ & \\
\hline IL-12/23 and IL-23 inhibitors & $40(34)$ & $42(33)$ & \\
\hline \multicolumn{4}{|l|}{ Occupational status } \\
\hline Student & $5(4)$ & $1(1)$ & $<0.001$ \\
\hline Unemployed & $3(3)$ & $10(8)$ & \\
\hline Unskilled worker & $13(11)$ & $18(14)$ & \\
\hline Craft worker & $8(7)$ & $8(7)$ & \\
\hline Office worker & $22(19)$ & $12(9)$ & \\
\hline Skilled worker & $14(12)$ & $10(8)$ & \\
\hline Manager & $27(23)$ & $13(10)$ & \\
\hline Retired & $26(22)$ & $56(44)$ & \\
\hline \multicolumn{4}{|l|}{ Educational level } \\
\hline Primary school & $37(31)$ & $79(62)$ & $<0.001$ \\
\hline Secondary school & $57(48)$ & $32(25)$ & \\
\hline College/university degree & $24(20)$ & $17(13)$ & \\
\hline \multicolumn{4}{|l|}{ Distance from the hospital } \\
\hline Living the same province & $75(64)$ & $91(71)$ & 0.449 \\
\hline $\begin{array}{l}\text { Living in another province } \\
\text { within the same region }\end{array}$ & $38(32)$ & $33(26)$ & \\
\hline Living in another region & $5(4)$ & $4(3)$ & \\
\hline $\begin{array}{l}\text { Being accompanied to the } \\
\text { hospital }^{\text {a }}\end{array}$ & $19(16)$ & $33(27)$ & 0.039 \\
\hline \multicolumn{4}{|c|}{ Frequency of visits to dermatologist in the last year } \\
\hline Every $<4$ months & $67(57)$ & $85(67)$ & 0.146 \\
\hline Every $4-6$ months & $50(42)$ & $40(31)$ & \\
\hline$>$ Every 6 months & $1(1)$ & $3(2)$ & \\
\hline
\end{tabular}


Table 1 continued

\begin{tabular}{lll} 
Patients who preferred & Patients who preferred in-person & $P$ value $^{*}$ \\
telemedicine $(n=118,47 \%)$ & visit $(n=128,52 \%)$ & \\
\hline
\end{tabular}

Exemption from insurance co-payment charges

\begin{tabular}{llll} 
Complete & $73(62)$ & $86(66)$ & 0.342 \\
Partial & $9(8)$ & $14(31)$ & \\
No exemption & $34(29)$ & $28(2)$ & 0.727 \\
$\begin{array}{l}\text { Previous experience with } \\
\text { telemedicine }\end{array}$ & $7(6)$ & $9(7)$ & $<0.001$ \\
$\begin{array}{l}\text { Previous use of video- } \\
\text { communication tools }\end{array}$ & $79(67)$ & $26(20)$ & \\
\hline
\end{tabular}

Data are presented as the mean \pm standard deviation (SD) or as frequencies ( $n$ with/without percentage in parentheses), as appropriate

PASI Psoriasis Area Severity Index

${ }^{*} P$ value was derived from the chi-squared test for categorical variables or the $t$ test for continuous variables. $P<0.05$ was considered to be statistically significant

${ }^{\text {a }}$ Data missing for 8 patients

questionnaire and learn of the reasons associated with patients' preferences. Secondly, the questionnaire was administered to consecutive patients with psoriasis $(n=10)$ to test patient comprehension of the questions. The text was then amended and rearranged to improve the ease of comprehension, and its final version was subsequently administered to those consecutive patients meeting the inclusion criteria. The questionnaire included a sociodemographic section capturing the following variables: sex, age, type of biological drug, educational level and occupational status, frequency of follow-up visits to the dermatologist in the last year, distance from the hospital $(\mathrm{km})$, need for accompaniment, exemption from insurance copayment charges and previous experience with digital video-communication tools (such as Skype ${ }^{\circledR}$, Zoom ${ }^{\circledR}$ or Google Meet ${ }^{\circledR}$ ) and telemedicine. In the second part of the questionnaire the patient was directly asked if he/she would prefer to have the next follow-up dermatological control visit in-person or by telemedicine and the reasons associated with the stated preference. The patients could indicate multiple answers among five different choices (Electronic Supplementary Material Table).

\section{Statistical Analysis}

Descriptive statistics in the form of means and standard deviations (SD) or frequencies and percentages for continuous and nominal variables, respectively, were used to present the data. The unpaired $t$ test and the chi-squared tests were used to compare the sociodemographic and clinical characteristics of participants stratified by their preference for telemedicine versus in-person visit. All of the variables associated with preference for telemedicine in the univariate analysis or representing a potential confounding factor were included in the multivariable logistic regression analysis. The strength of associations was expressed in terms of odds ratios (OR) with 95\% confidence intervals $(\mathrm{CI}) . P$ values $<0.05$ were considered to be statistically significant. Statistical analyses were performed using Stata version 13 (Stata Corp., College Station, TX, USA).

\section{Compliance with Ethics Guidelines}

This research was conducted in accordance with the Helsinki Declaration of 1964 and its later 
Table 2 Univariate and multivariate regression model assessing associations with sociodemographic and clinical characteristics of the 246 study participants and their preference for telemedicine

\begin{tabular}{|c|c|c|c|c|}
\hline \multirow[t]{2}{*}{ Variable } & \multicolumn{2}{|l|}{ Univariate } & \multicolumn{2}{|l|}{ Multivariate } \\
\hline & OR (95\% CI) & $P$ & OR (95\% CI) & $P$ \\
\hline Age $\geq 60$ years & $0.30(0.17-0.53)$ & $<0.001$ & $0.30(0.10-0.90)$ & 0.031 \\
\hline Sex (male) & $1.61(0.97-2.66)$ & 0.067 & $0.35(0.12-1.07)$ & 0.065 \\
\hline Educational level $\geq$ secondary school & $1.85(1.01-3.37)$ & 0.046 & $1.18(0.41-3.37)$ & 0.750 \\
\hline Skilled job ${ }^{\mathrm{a}}$ & $2.01(1.13-3.58)$ & 0.017 & $1.51(0.51-4.41)$ & 0.455 \\
\hline Complete exemption from insurance co-payment charges & $1.51(0.68-3.40)$ & 0.315 & $0.85(0.29-2.51)$ & 0.772 \\
\hline Being accompanied to the hospital & $0.52(0.28-0.97)$ & 0.041 & $1.03(0.34-3.18)$ & 0.957 \\
\hline Frequency of visits to dermatologist $\leq$ every 4 months & $0.51(0.05-5.65)$ & 0.579 & $0.27(0.02-4.00)$ & 0.270 \\
\hline Living in another province or farther & $1.53(0.89-2.63)$ & 0.127 & $1.14(0.38-3.49)$ & 0.812 \\
\hline Previous experience with video-communication tools & $8.42(4.04-17.57)$ & $<0.001$ & $10.75(3.61-32.03)$ & $<0.001$ \\
\hline
\end{tabular}

Sample size $n=246$

CI Confidence interval, $O R$ odds ratio

a Including craft workers, office workers and managers

amendments. The study was approved by the Institutional Review Board and patients provided written informed consent to participate.

\section{RESULTS}

A total of 246 consecutive adult patients with psoriasis, of whom 120 were men (49\%) and 125 were women $(51 \%)$, with a mean age $( \pm S D)$ of $53.1 \pm 14.2$ years, were recruited to the study. The clinical and sociodemographic characteristics of the study participants stratified according to their preference for telemedicine versus inperson visit are reported in Table 1. Overall, 74 of the $246(30 \%)$ patients were treated with TNF- $\alpha$ inhibitors, 90 (37\%) with IL-17A inhibitors and 82 (33\%) with IL-12/23 or IL-23 inhibitors. Of the 246 patients, 118 (48\%) answered that they would choose telemedicine for their next scheduled visits rather than an in-person visit. Patients who preferred telemedicine were younger than those who chose an in-person visit with a mean $( \pm$ SD) age of $49.3 \pm 14.3$ years (vs. $56.7 \pm 13.2 ; P<0.001$ ). The educational and occupational backgrounds were significantly different in the two groups, with a higher percentage of persons with a lower-level educational status and retired persons among those patients who preferred an in-person visit (62 vs. $31 \%$ and 44 vs. $22 \%$, respectively; $P<0.001)$. Conversely, a higher proportion of patients with a managerial job chose telemedicine. Patients who needed assistance coming to the hospital were more likely to prefer an in-person visit ( 27 vs. $16 \% ; P=0.039$ ). Finally, very few patients reported previous experience with telemedicine, and this variable did not differ between the two groups; conversely, a higher proportion of patients with previous experience with video-communication tools preferred telemedicine versus in-person visit (67 vs. $20 \% ; P<0.001$, respectively). Multivariate logistic regression analysis revealed that previous experience with video-communication tools was a significant predictor for telemedicine preference (OR 10.75; 95\% CI 3.61-32.03) while age $>60$ years was negatively associated with this choice (OR $0.30 ; 95 \%$ CI 0.10-0.90) (Table 2).

The most frequently reported reason for preferring telemedicine was the possibility of 
saving time $(75 \%)$, followed by convenience $(50 \%)$, possibility of saving money (38\%) and safety in relation to the risk represented by the SARS-CoV-2 pandemic (38\%), as shown in Fig. 1. In contrast, more than half of the patients $(56 \%)$ who preferred in-person visits reported being unable to use video-communication tools and 38\% lacked an internet connection at home. Another common reason for preferring in-person visits ( $44 \%$ of patients) was the need for direct contact with the physician without any technological barriers. All patients invited to participate in the survey agreed to answer all questions.

\section{DISCUSSION}

National health authorities in Italy have recently required physicians to implement on a

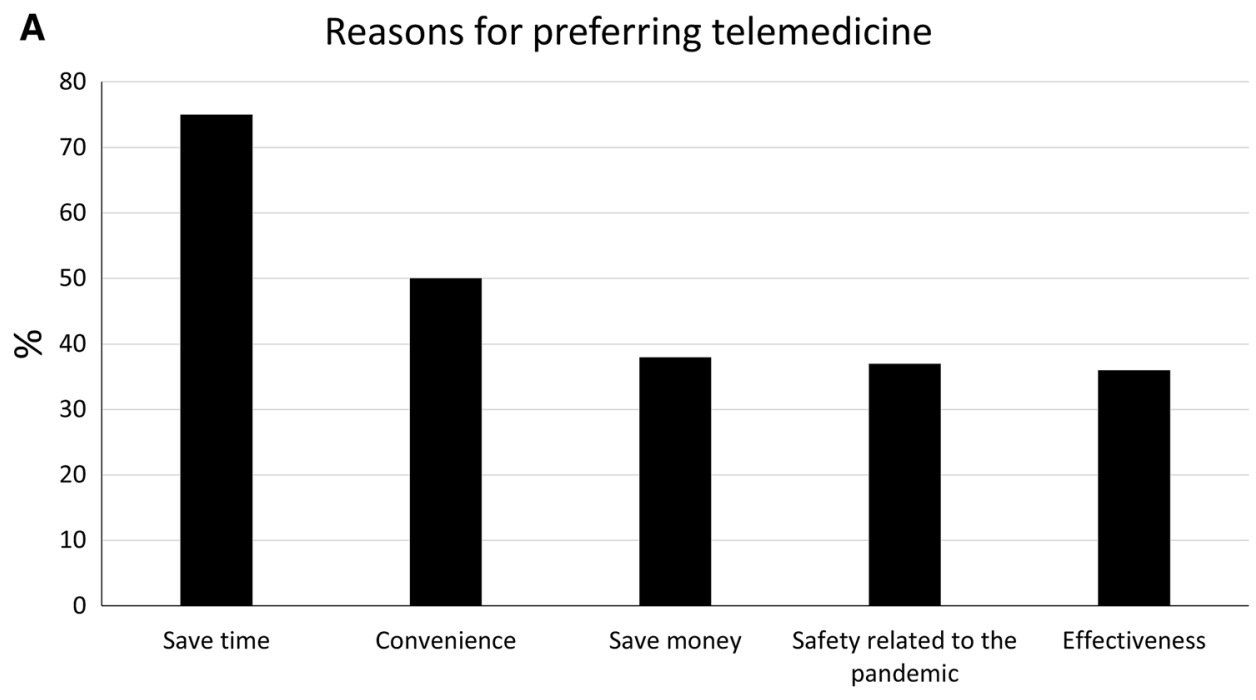

B Reasons for preferring in-person visit

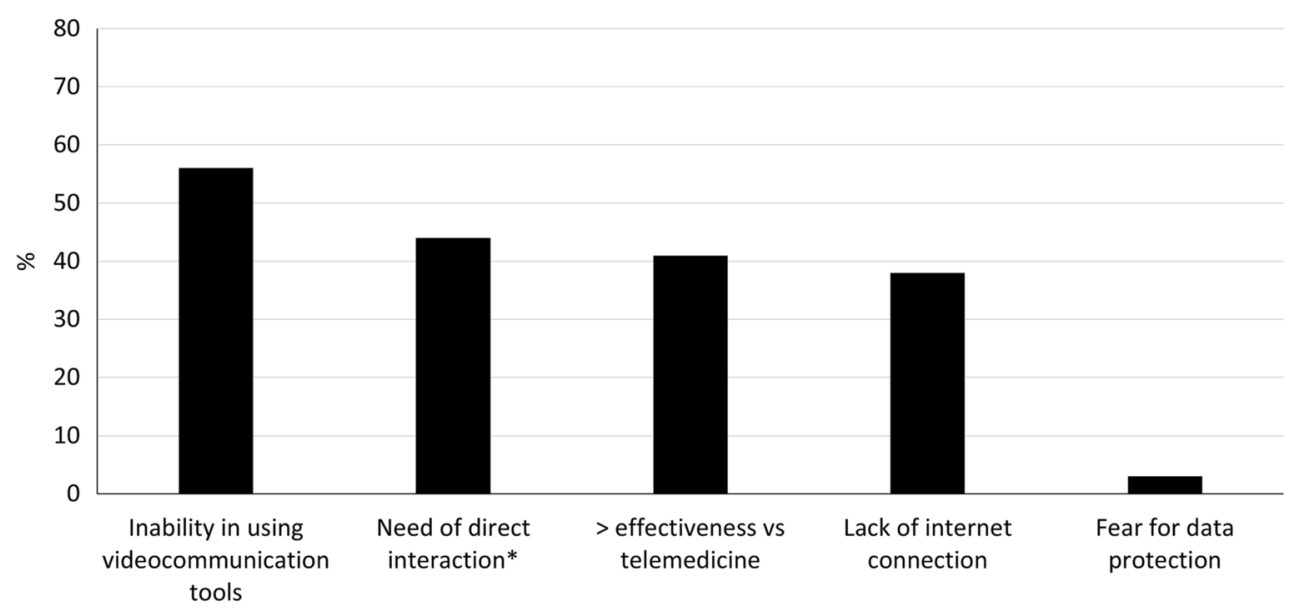

*A need of having a direct interaction with the dermatologist without intersposed technological barriers

Fig. 1 Reasons for preferring video-communication tools (i.e. telemedicine) (a) or in-person visits (b) for the next scheduled visit presented as the percentage of patients $(n=$
246). Patients could indicate multiple answers among five different choices 
large scale the use of telemedicine in their daily care activities; however, no criteria for selecting the type of disorders and/or patients' characteristics that would indicate the best candidates for telemedicine were provided [6]. In the present study, we found that about one half of the included patients with stable plaque psoriasis on maintenance therapy with biological drugs preferred that their next scheduled visit to the dermatologist be conducted through telemedicine rather than in-person. We investigated this group of patients because their diagnosis is known, their treatment already established and the routine visit usually ends in a confirmation of the therapy in progress. Interestingly, in an earlier study conducted in a primary care setting the preference for telemedicine in a naive patient population was reported to be only $14 \%$ [7]. The analysis of our patients' characteristics showed that the choice of telemedicine was strongly associated with being younger, being confident with the videocommunication tools, having a higher educational level and/or a managerial job and having accessibility to an internet connection at home. These results indicate that a possible negative consequence of a random and large-scale implementation of telemedicine may be inequal access to care within the National Health System to the detriment of those who are older, have a lower level of education and who have either no access to the internet or are not confident with the use of video-communication tools. However, this technology-specific barrier could be overcome through training, changes in management techniques and alternating the delivery of healthcare by telemedicine and personal patient-to-provider interaction [8].

The most reported reasons for preferring telemedicine were saving time, feasibility and safety issues related to the COVID-19 pandemic. It is quite clear that the SARS-Cov-2 pandemic has profoundly influenced the management of in-person care of patients affected by chronic conditions because of the many restrictions for elective and non-urgent visits, particularly during the lockdown $[9,10]$. Notably, in response to the COVID-19 pandemic, cancer screening has been suspended, routine diagnostic work deferred and only urgent symptomatic cases prioritized for diagnostic intervention, with a potential for a substantial increase in the number of avoidable cancer deaths in England due to diagnostic delays [11].

Another relevant reason for preferring the inperson visit option was the need of the patient to directly interact with the dermatologist without any technological barriers. Whether the adoption of telemedicine will compromise patient-physician interaction is currently being debated [12]. Although there is currently no evidence that the patient-physician relationship is compromised when telemedicine is used, some authors do believe that telemedicine might impair that relationship [13, 14]. Conversely, others have reported that telemedicine, even in an oncological setting, is perceived as a safe and effective option and that it does not compromise medical care or the patient-physician relationship [15]. A systematic review of the barriers associated with telemedicine identified 33 different issues in the 30 articles in the review, including technically challenged staff, resistance to change, cost, reimbursement, age of patient, educational level of patient and written and verbal communication impairment $[16,17]$.

Another aspect that needs to be discussed is which dermatological disorders are good candidates to be followed in telemedicine. In our opinion, the best candidates are patients with established chronic skin disorders, such as psoriasis, acne, rosacea and eczema, while other conditions requiring a thorough total body skin examination or special device, such as dermoscopy, are less likely candidates for telemedicine [18]. Interestingly, teledermatology is preferred by the younger patient population with more benign skin conditions, compared to those with neoplastic processes and severe diseases that are more prone for in-person visits to the dermatologist [19]. As early as 2012, teledematology was found to be a promising and reliable tool for the long-term management of patients with psoriasis on systemic treatment (e.g. biologics), and also recommended by those patients who tried it $[20,21]$. The effectiveness in assessing the severity of psoriasis was even evaluated in a randomized controlled trial in 
296 patients, with the results demonstrating that telemedicine was as effective as the inperson visit [22]. Telemedicine could provide a cost-effectiveness service with an important saving of money by patients [18]. A study on store and forward teledermatology demonstrated that it saves patients from US\$ 33.23 to US\$230.35 per visit [23].

Although in our study included very few patients who expressed their concern for data protection, a secure network for the transmission and storage of confidential patient data and images is essential, and data should be protected to safeguard patient privacy [24]. Another issue to be considered is to what extent the telemedicine could allow the dermatologist to accurately monitor the safety of the treatment with biologicals.

The study is burdened by a number of limitations. First, the questionnaire used was not validated. Nevertheless, the purpose of the designed descriptive questionnaire was exploratory, with the aim to investigate the propensity of patients to choose telemedicine compared to in-person visit. Another limitation is the small sample size, with the patients restricted to those attending two medical centers. It is plausible that the results could be generalized to other Italian areas, but not to other European and extra-European cultures. Finally, we could not address whether the longterm follow-up of the same patient with telemedicine is possible. Further studies are needed to investigate these issues.

\section{CONCLUSION}

In conclusion, a positive attitude toward telemedicine was found in almost half of patients affected by psoriasis in maintenance therapy with biological drugs. Our results suggest that providing patients with training related to telecommunication technologies might increase patients' preference for telemedicine.

\section{ACKNOWLEDGEMENTS}

We thank the participants of the study.
Funding. This research was supported by Fondazione Cariplo, Fondazione Veronesi, Impact of COVID19 infection on patients affected by inflammatory skin diseases on immuno-suppressive therapies (COVISKIN); ID 1,833,073 rif. 2020-1363. No Rapid Service Fee was received by the journal for the publication of this article.

Authorship. All named authors meet the International Committee of Medical Journal Editors (ICMJE) criteria for authorship for this article, take responsibility for the integrity of the work as a whole, and havegiven their approval for this version to be published.

Authors contributions. P. Gisondi, S. Di Leo, F. Bellinato, S. Cazzaniga, S. Piaserico and L. Naldi contributed equally to concept and design of the study. F. Bellinato, S. Di Leo and S. Cazzaniga performed the statistical analysis. P. Gisondi, S. Di Leo and F. Bellinato contributed to drafting the manuscript. L. Naldi did the final revision of the manuscript.

Disclosures. P. Gisondi has received consultation fees from Abbvie, Amgen, Almirall Eli Lilly, Janssen, Leo-pharma, Novartis, Sanofi, Sandoz and UCB as a speaker and/or participant in advisory boards. S. Piaserico has received consultation fees from Abbvie, Almirall, Celgene, Janssen, Leo-pharma, Eli Lilly, Novartis, Sandoz and UCB as a speaker and/or participant in advisory boards. L. Naldi has received consultation fees from Abbvie, Amgen, Boehringer Inghelheim, Celgene, Eli Lilly, IBSA, Menarini, Janssen, Novartis and Sanofi. F. Bellinato, S. Di Leo and S. Cazzaniga have nothing to disclose.

Compliance with ethics guidelines. This research was conducted in accordance with the Helsinki Declaration of 1964 and its later amendments. The study was approved by the Institutional Review Board and patients provided written informed consent to participate.

Data availability. Data are available in the tables and ESM table. 
Open Access. This article is licensed under a Creative Commons Attribution-NonCommercial 4.0 International License, which permits any non-commercial use, sharing, adaptation, distribution and reproduction in any medium or format, as long as you give appropriate credit to the original author(s) and the source, provide a link to the Creative Commons licence, and indicate if changes were made. The images or other third party material in this article are included in the article's Creative Commons licence, unless indicated otherwise in a credit line to the material. If material is not included in the article's Creative Commons licence and your intended use is not permitted by statutory regulation or exceeds the permitted use, you will need to obtain permission directly from the copyright holder. To view a copy of this licence, visit http://creativecommons.org/licenses/by$\mathrm{nc} / 4.0 /$.

\section{REFERENCES}

1. Gisondi P, Piaserico S, Conti A, et al. Dermatologists and SARS-CoV-2: the impact of the pandemic on daily practice. J Eur Acad Dermatol Venereol. 2020;34:1196-201.

2. Su MY, Lilly E, Yu J, et al. Asynchronous teledermatology in medical education: Lessons from the COVID-19 pandemic. J Am Acad Dermatol. 2020;83:e267-8.

3. Su MY, Das S. Expansion of asynchronous teledermatology during the COVID-19 pandemic. J Am Acad Dermatol. 2020;83:e471-2.

4. Su MY, Smith GP, Das S. Trends in teledermatology use during clinic reopening after COVID-19 closures. J Am Acad Dermatol. 2021;84:e213-4.

5. WHO Global Observatory for eHealth. Telemedicine: opportunities and developments in Member States: report on the second global survey on eHealth. Geneva: World Health Organization. 2010. https://apps.who.int/iris/handle/10665/ 44497. Accessed 15 April 2021.

6. La conferenza permanente per i rapporti tra lo stato, le regioni e le province autonome di Trento e di Bolzano. 2020. http://www.statoregioni.it/media/ 3221/p-3-csr-rep-n-215-17dic2020.pdf. Accessed 15 April 2021.
7. Reed ME, Huang J, Graetz I, et al. Patient characteristics associated with choosing a telemedicine visit vs office visit with the same primary care clinicians. JAMA Netw Open. 2020;3:e205873.

8. Scott Kruse C, Karem P, Shifflett K, et al. Evaluating barriers to adopting telemedicine worldwide: A systematic review. J Telemed Telecare. 2018;24: $4-12$.

9. Kwatra S, Sweren R, Grossberg A. Dermatology practices as vectors for COVID-19 transmission: A call for immediate cessation of nonemergent dermatology visits. J of Am Acad Dermatol. 2020;82: e179-80.

10. World Health Organization. COVID-19: operational guidance for maintaining essential health services during an outbreak: interim guidance, 25 March 2020. Geneva: World Health Organization. 2020. https://apps.who.int/iris/handle/10665/331561. Accessed 15 April 2021.

11. Maringe C, Spicer J, Morris M, et al. The impact of the COVID-19 pandemic on cancer deaths due to delays in diagnosis in England, UK: a national, population-based, modelling study. Lancet Oncol. 2020;21:1023-34.

12. Miller EA. Telemedicine and doctor-patient communication: an analytical survey of the literature. J Telemed Telecare. 2001;7:1-17.

13. US Institute of Medicine Committee on Evaluating Clinical Applications of Telemedicine. In: Field MJ, ed. Telemedicine: a guide to assessing telecommunications in health care. Washington, DC: US National Academies Press; 1996.

14. Wootton R, Darkins A. Telemedicine and the doctor-patient relationship. J R Coll Physicians Lond. 1997;31:598-9.

15. Hasson SP, Waissengrin B, Shachar E, et al. Rapid implementation of telemedicine during the COVID-19 pandemic: perspectives and preferences of patients with cancer. Oncologist. 2021;26(4): e679-85. https://doi.org/10.1002/onco.13676.

16. Linggonegoro DW, Sanchez-Flores X, Huang JT. How telemedicine may exacerbate disparities in patients with limited English proficiency. J Am Acad Dermatol. 2021;84(6):16:E289-90.

17. Trettel A, Eissing L, Augustin M. Telemedicine in dermatology: findings and experiences worldwide-a systematic literature review. J Eur Acad Dermatol Venereol. 2018;32:215-24.

18. Perkins S, Cohen JM, Nelson CA, et al. Teledermatology in the era of COVID-19: Experience of an 
academic department of dermatology. J Am Acad Dermatol. 2020;83:e43-4.

19. Uscher-Pines L, Malsberger R, Burgette L, et al. Effect of teledermatology on access to dermatology care among medicaid enrollees. JAMA Dermatol. 2016;152:905.

20. Balato N, Megna M, Di Costanzo L, et al. Educational and motivational support service: a pilot study for mobile-phone-based interventions in patients with psoriasis: Telepsoriasis services. Br J Dermatol. 2013;168:201-5.

21. Koller S, Hofmann-Wellenhof R, Hayn D, et al. Teledermatological monitoring of psoriasis patients on biologic therapy. Acta Derm Venereol. 2011;91: 680-5.

22. Armstrong AW, Chambers CJ, Maverakis E, et al. Effectiveness of online vs in-person care for adults with psoriasis: A randomized clinical trial. JAMA Netw Open. 2018;1:e183062.

23. Sharma P, Nguyen BM, Yang FSC. A patient-centric cost analysis of store-and-forward teledermatology. Int J Dermatol. 2020;59:e43-5.

24. Tensen E, van der Heijden JP, Jaspers MWM, et al. Two decades of teledermatology: Current status and integration in national healthcare systems. Curr Dermatol Rep. 2016;5:96-104. 